\title{
WYKAZ DRUKOWANYCH PRAC KS. PROF. DRA HAB. AUGUSTYNA ECKMANNA
}

\author{
A. Książki \\ 1. Dialog świętego Augustyna ze światem pogańskim w świetle jego korespondencji, \\ Lublin: Redakcja Wydawnictw KUL 1987. \\ 2. Symbol Apostolski w pismach świętego Augustyna, Lublin: TN KUL 1999. \\ 3. Przebóstwienie człowieka w pismach wczesnochrześcijańskich, Lublin: TN KUL \\ 2003.
}

\section{B. Redakcje książek}

1. Obraz Boga w Psatterzu, red. A. Eckmann - S. Łach - A. Tronina, Studia Teologiczne, t. 3, Lublin 1982.

2. Pisma świętego Augustyna o małżeństwie i dziewictwie, Przekład i komentarz, red. A. Eckmann, Lublin 2003

3. W poszukiwaniu człowieka w człowieku. Chrześcijańskie korzenie nadziei, red. S. Nowosad - A. Eckmann - T. Adamczyk, Materiały IV Kongresu Kultury Chrześcijańskiej, Lublin 2012.

\section{Artykuly}

1. Tradycyjne znaczenie rzeczownika ,to onoma” u Jana Chryzostoma $w$ „Expositiones in Psalmos”, RH 25 (1977) z. 3, 55-63.

2. „Onoma tu Theu” jako określenie Boga i Jego przymiotów w „Expositiones in Psalmos" Jana Chryzostoma, RTK 25 (1978) z. 4, 203-218.

3. Postawa Izraela wobec imienia Bożego w świetle Psałterza, SPelp 9 (1978) 183-207.

4. Hieronim ze Strydonu. Nauka w służbie rozumienia i interpretacji Pisma świętego, AK 71 (1979) z. 3 (422), 422-429.

5. Milczący świadek, „Orędownik Diecezji Chełmińskiej” (1979) z. 11-12, 426-431.

6. Pismo święte w życiu i nauczaniu Ojców Kościoła, AK 71 (1979) z. 2 (421), 201-212.

7. Šèm Boga w Psalmach, SPelp 10 (1979) 7-64.

8. Argumenty filozoficzno-religijne Maksyma z Madaury w liście do św. Augustyna z Hippony broniace tradycyjnej wiary Rzymian, RTK 28 (1981) z. 4, 145-148.

9. Psalm 8 w świetle badań filologiczno-egzegetycznych, RBL 34 (1981) nr 4, 194-203.

10. Stosunek pogaństwa do chrześcijaństwa w korespondencji i pismach św. Augustyna, RH 29 (1981) z. 3, 93-108.

11. Znaczenie imienia Bożego w Psatterzu, w: Obraz Boga w Psałterzu, red. A. Eckmann - S. Łach - A. Tronina, Studia Teologiczne, t. 3, Lublin 1982, 143-168.

12. Dialog listowny św. Augustyna z Woluzjanem, RH 31 (1983) z. 3, 63-89.

13. Problemy biblijne i społeczno-polityczne w Liście świętego Augustyna do Marcelina, VoxP 3 (1983) z. 4, 88-104.

14. Dialog św. Augustyna z Naktariuszem, RH 32 (1984) z. 3, 57-94. 
15. Dyskusja św. Augustyna z Maksymem z Madaury, SPelp 15 (1984) 149-160.

16. List św. Augustyna do pogan w Madaurze, VoxP 4 (1984) z. 6-7, 137-146.

17. Problemy filozoficzno-religijne $w$ korespondencji św. Augustyna z Maksymem z Madaury, RH 33 (1985) z. 3, 103-123.

18. Starożytna rodzina grecka i rzymska, VoxP 5 (1985) z. 8-9, 29-50.

19. Kultura klasyczna u św. Augustyna, VoxP 6 (1986) z. 10, 45-60.

20. Sw. Augustyn - duszpasterz, VoxP 7 (1987) z. 12-13, 137-153.

21. Celibat kapłanów wczoraj $i$ dziś, w: Materiały z konferencji rektorów wyższych seminariów duchownych diecezjalnych i zakonnych w Polsce, Łódź 1988, 29-89.

22. Liturgia i teologia chrztuśw. Augustyna w Mediolanie, VoxP 8 (1988) z. 14, 101-118.

23. Moc poezji w ujęciu św. Augustyna, VoxP 8 (1988) z. 15, 811-816.

24. Stosunek św. Augustyna do państwa rzymskiego, w: Chrześcijanie a życie publiczne w Cesarstwie Rzymskim III-IV wiek, red. J. Śrutwa, Lublin 1988, 213-261.

25. Św. Augustyn - duszpasterz [dokończenie], VoxP 8 (1988) z. 14, 306-313.

26. Osobowość dobrego katechety w ujęciu św. Augustyna, VoxP 10 (1990) z. 18, 113-119.

27. Znajomość św. Augustyna w Kościele Wschodnim, VoxP 10 (1990) z. 18, 199-212.

28. Pagan religion in Roman Africa at the turn of the $4^{\text {th }}$ century as reflected in the Letters of St. Augustine, w: Byzantina et Slavica Cracoviensia I. Paganism in the Later Roman Empire and in Byzantium, ed. by M. Salamon, Cracow 1991, 61-71.

29. Celibat kapłanów wczoraj $i$ dziś (w perspektywie patrystycznej, historycznej $i$ wspótczesnej) w: Rady ewangeliczne w formacji kapłańskiej, red. J. Buxakowski, Pelplin 1992, 80-116 (poprawiona i uzupełniona wersja artykułu z 1988 r.).

30. Chrzest w nauczaniu św. Ambrożego, w: Chrzest-nowość życia, red. A. J. Nowak - W. Słomka, Homo meditans X, Lublin 1992, 49-56.

31. Św. Augustyn. Wirtuoz języka i stylu (Epistola 150), VoxP 11-12 (1991-1992) z. 20-23, 451-462.

32. Dziecko $w$ Biblii, w: Rodzina $w$ starożytnym Rzymie. Materiaty z konferencji naukowej, Zacisze 20-21.05.1991 r. zorganizowanej przez Katedrę Historii Wychowania WSP w Bydgoszczy, red. J. Jundziłł, Bydgoszcz 1993, 207-219.

33. Nauka świętego Augustyna o pokorze jako podstawie ascezy chrześcijańskiej, w: Wczesnochrześcijańska asceza. Zagadnienia wybrane, red. F. Drączkowski - J. Pałucki, Lublin 1993, 83-97.

34. Nauczanie $i$ wychowanie $w$ teorii i praktyce św. Augustyna, w: Chrześcijańskie dziedzictwo bizantyńsko-słowiańskie. VI Kongres Teologów Polskich, Lublin 1214 IX 1989, red. A. Kubiś - M. Rusecki, Lublin 1994, 319-320.

35. Sekcja Filologii Klasycznej, w: Księga Pamiątkowa w 75-lecie Katolickiego Uniwersytetu Lubelskiego, red. M. Rusecki, Lublin 1994, 317-318.

36. Znajomość św. Augustyna w Kościele Wschodnim, w: Chrześcijańskie dziedzictwo bizantyńsko-słowiańskie. VI Kongres Teologów Polskich, Lublin 12-14 IX 1989, red. A. Kubiś - M. Rusecki, Lublin 1994, 293-296.

37. Teologia kapłaństwa w pismach św. Augustyna, VoxP 13-15 (1993-1995) z. 2429, 131-160.

38. Czy jest możliwa pokojowa koegzystencja między narodami? Koncepcja pokoju $i$ wojny w nauczaniu Ojców Kościoła, w: Patrystyczne dziedzictwo społecznej nauki Kościoła, red. T. Makowski, Gniezno 1996, 57-72.

39. Koncepcja przyjaźni w dziełach św. Augustyna, RH 44 (1996) z. 3, 231-241. 
40. Maryja w tajemnicy Kościoła wedtug św. Augustyna, SPelp 24 (1996) 149-161.

41. Troska o ubogich w nauczaniu i działalności świętego Augustyna, VoxP 16 (1996) z. 30-31, 161-182.

42. Historia $w$ świetle pism św. Augustyna, w: Studia nad kultura antyczna, red. J. Rostropowicz, Opole 1997, 113-120.

43. Święty Augustyn jako komentator Symbolu Apostolskiego, w: Symbol Apostolski w nauczaniu i sztuce Kościoła do Soboru Trydenckiego, red. R. Knapiński, Lublin 1997, 161-177.

44. Troska o dobro ojczyzny w teorii i praktyce św. Augustyna, w: W postudze Stowa Pańskiego. Księga pamiątkowa poświęcona ks. prof. dr. hab. J. Kudasiewiczowi z okazji 70-lecia urodzin, red. Bielecki - H. Ordon - H. Witczyk, Kielce 1997, 412-421.

45. Sztuka wymowy w teorii i praktyce św. Augustyna, w: Słowo Boga i drogi człowieka, red. Z. Machnikowski, Tczew - Pelplin 1998, 155-174.

46. Św. Ambroży jako duchowy mistrz św. Augustyna, VoxP 18 (1998) z. 34-35, 195-198.

47. Grzech pierworodny jako źródło cierpień człowieka u św. Augustyna, w: Grzech pierworodny, red. A. Bandura - A. Baron - T. Górski i in., Kraków 1999 = ŹMT 12, 109-125.

48. Pisarze wczesnochrześcijańscy wobec kultury klasycznej, RH 47 (1999) z. 3, 89-103.

49. Wielkość i godność kobiety wedtug świętego Augustyna, w: Kobieta w starożytności chrześcijańskiej. Materiały Sympozjum Patrystycznego 22.10.1998 ATK, red. I. Salamonowicz-Górska - T. Skibiński - S. Strękowski, Warszawa $1999=$ SACh $14,32-42$.

50. Incarnatio Christi w pismach św. Augustyna. Istota i cel, VoxP 20 (2000) z. 38-39, 237-245.

51. Obraz Boga ws św. Augustyna wykładzie pierwszego artykułu wiary, w: Obraz Boga Ojca w kulturze, red. M. Ołdakowska-Kuflowa - U.M. Mazurczak, Lublin 2000, 37-54.

52. Dobroć i piękno ciała ludzkiego w pismach św. Augustyna, „Classica Wratislaviensia" 22 (2001) nr 2287, 161-168.

53. Święty Augustyn dziś, VoxP 21 (2001) z. 40-41, 305-316.

54. Kaptan a kobieta, „Dobry Pasterz” 27 (2002) t. 40-41, 115-123.

55. Osobowość dobrego katechety $w$ świetle De catechizandis rudibus świętego Augustyna (Die Persönlichtkeit eines guten Katecheten im Lichte von De catechizandis rudibus des hl. Augustinus), „Keryks”. Międzynarodowy Przegląd Katechetyczno-Pedagogicznoreligijny: Internationale ReligionspädagogischKatechetische Rundschau 1 (2002) 53-60.

56. Przebóstwienie człowieka w pismach świętego Augustyna. Pojęcia i określenia, SPelp 33 (2002) 245-264.

57. Obraz Boga w człowieku wedtug świętego Augustyna, RH 51 (2003) z. 3, 75-84.

58. Przebóstwienie człowieka $w$ świetle pism wczesnochrześcijańskich, w: Filozofować w kontekście teologii. Religia - nauka - łaska, red. P. Moskal, Religia i Mistyka, t. 1, Lublin 2003, 21-31.

59. Wprowadzenie. Święty Augustyn o matżeństwie i dziewictwie, w: Pisma świętego Augustyna o matżeństwie i dziewictwie. Przekład i komentarz, red. A. Eckmann, Lublin 2003, 5-49. 
60. Deification of Man in St. Ambrose's writings, w: Byt czy dobro? Metamorfozy neoplatonizmu, red. A. Kijewska, Lublin 2004, 199-210.

61. Przebóstwienie człowieka w rzeczywistości Kościoła wświetle pism wczesnochrześcijańskich, w: Świadek Chrystusowych cierpień (1 P 5, 1), red. J. Morawa, Studia - Papieska Akademia Teologiczna w Krakowie. Wydział Teologiczny, t. 10, Kraków 2004, 403-424.

62. Święty Augustyn wobec religii niechrześcijańskich, w: Filozofować w kontekście teologii. Problem religii prawdziwej, red. P. Moskal, Religia i Mistyka, t. 2, Lublin 2004, 149-160.

63. Siła madrości wedtug świętego Augustyna, w: Lumen Christi tantum in Ecclesia, red. T. Paszkowska, Lublin 2005, 445-455.

64. Święty Augustyn dla kultury Europy, w: Kościół w życiu publicznym. Teologia polska i europejska wobec nowych wyzwań, t. 3: Dyskusje, komunikaty, uzupetnienia, dokumenty końcowe, red. K. Góźdź i in., Lublin 2005, 279-312.

65. Augustyńskie Credo, w: Św. Augustyn dzisiaj. Colloquium Augustinianum. 1650. rocznica urodzin św. Augustyna z Hippony, red. W. Dawidowski, Kraków 2006, 83-90.

66. Znaczenie „petra” (Mt 16, 18) w interpretacji świętego Augustyna, VoxP 26 (2006) z. 49, 167-178.

67. Jan Paweł II a 1600. rocznica nawrócenia św. Augustyna, VoxP 27 (2007) z. 5051, 165-172.

68. Koncepcja sztuki w pismach świętego Augustyna, VoxP 28 (2008) z. 52, s.171-185.

69. Biblijne podstawy Chryzostomowego programu wychowania dzieci, VoxP 29 (2009) z. 53-54, 329-335.

70. Filozofia w życiu i twórczości św. Augustyna, w: Gaudium in litteris. Księga Jubileuszowa Księdza Arcybiskupa Profesora Stanisława Wielgusa, red Janeczek W. Bajor - M.M. Maciołek, Lublin 2009, 721-740.

71. Poszukiwanie $i$ widzenie Boga $w$ życiu i nauczaniu świętego Augustyna, VV 16 (2009) 211-228.

72. Bogactwo i ubóstwo w pismach świętego Augustyna, w: Zbytek i ubóstwo w starożytności i średniowieczu, red. L. Kostuch - K. Ryszewska, Kielce 2010, 263-271.

73. Kapłaństwo stużebne biskupa i prezbitera w pismach świętego Augustyna, VV 17 (2010) 275-302.

74. Kult męczenników afrykańskich w pismach św. Augustyna, VoxP 30 (2010) 55, 183-188.

75. Problem estetyczny i moralny teatru w pismach św. Augustyna, „Roczniki Kulturoznawcze" 1 (2010) 135-144.

76. Biskupia troska św. Augustyna o wychowanie $i$ wykształcenie kapłanów, VV 21 (2012) 241-252.

77. Kościół w życiu i nauczaniu św. Augustyna, w: Fructus Spiritus est Caritas. Księga jubileuszowa ofiarowana Księdzu Profesorowi Franciszkowi Draczkowskiemu z okazji siedemdziesiatej rocznicy urodzin, czterdziestopięciolecia święceń kapłańskich i trzydziestopięciolecia pracy naukowej, red. M. Wysocki, Lublin 2011, 133-142.

78. Mulier fortis docta sapiens, RH 58-59 (2010-2011) z. 3, 5-6.

79. Obraz ludzi starszych w pismach świętego Augustyna, VoxP 31 (2011) z. 56, 313-320. 
80. Święty Augustyn o greckich autorach, w: Starożytny dramat. Teoria - Praktyka - Recepcja. Księga pamiątkowa ku czci Profesorów Roberta R. Chodkowskiego i Henryka Podbielskiego, red. K. Narecki, Lublin 2011, 149-157.

81. Świętego Augustyna krytyka politeizmu, w: Wczesne chrześcijaństwo a religie, red. I. Ledwoń - M. Szram, Lublin 2012, 201-214.

82. Świętego Augustyna przeżywanie starości w świetle jego listów, VoxP 32 (2012) z. 57, 155-166.

83. Radość (gaudium) w nauczaniu Świętego Augustyna, VoxP 32 (2012) t. 58, 307-314.

\section{Hasła encyklopedyczne}

1. Diana, EK III 1292-1293.

2. Eranos, EK IV 1060-1061.

3. Euhemeryzm, EK IV 1297-1299.

4. Euhemeryzm, PEF III 316-317.

5. Fecjałowie, EK V 86.

6. Grecka kultura, EK VI 125-126.

7. Hades, EK VI 454.

8. Hades, PEF IV 168-169.

9. Haoma, EK VI 545-546.

10. Helios, EK VI 654-655.

11. Hermafrodyta, EK VI 761.

12. Hippo Diarrhytus, EK VI 932.

13. Hirina, EK VI 733.

14. Hozjusz z Kordowy, EK VI 1261.

15. Igrzyska, EK VII 3-6.

16. Jerzy z Arabii, EK VII 1232.

17. Jerzy Choiroboskos, EK VII 1233.

18. Jowinian, EK VIII 101-102.

19. Jowisz, Iuppiter, EK VIII 102.

20. Julian z Eklanum, EK VIII 238-239.

21. Junona, Iuno, EK VIII 260-261.

22. Kartagina, Carthago, EK VIII kol. 900-901.

23. Kasandra, Aleksandra, EK VIII kol. 935.

24. Klaudian Mamert, EK IX 77-78.

25. Korneliusz, św., EK IX 858.

26. Kreskoniusz, EK IX 1267-1268.

27. Libaniusz, EK X 938-939.

28. Makrobiusz, EK XI 893.

29. Monika, EK XIII 118-119.

30. Państwo Boże, EK XIV 1252-1255.

31. Patmos, EK XV 34-35.

32. Penaty, EK XV 263-264.

33. Penelopa, EK XV 265.

34. Pergamon, EK XV 292-293.

35. Persjusz, EK XV 329-330.

36. Pliniusz Młodszy, EK XV 820-821. 
37. Pliniusz Starszy, EK XV 819-820.

38. Proba, EK XVI 409-410.

39. Salwian, EK XVII 952-954.

40. Seneka, EK XVII 1414-1417.

41. Świderkówna Anna, EK XIX 353-355.

42. Terencjusz, EK XIX 707.

\section{E. Przekłady}

1. Polski przekład bulli nominacyjnej ks. bpa Jana Szlagi Solent Summi Pontifices, „Orędownik Diecezji Chełmińskiej” 39 (1988) z. 11-12, 73-74.

2. Kolekty do Psalmów, w: Antologia modlitwy wczesnochrześcijańskiej, red. L. Małunowiczówna, pracę ukończył i do druku przygotował L. Gładyszewski, Starożytne Teksty Chrześcijańskie, III, Lublin 1993, 367-392.

\section{F. Recenzje}

1. H. Wójtowicz, Studia nad Nonnosem, Lublin 1980 - VoxP 1 (1981) z. 1, 72-77.

2. Św. Augustyn, Antologia pism o matżeństwie i rodzinie, cz. I: Wartości matzeństwa (De bono coniugali), tłum. W. Eborowicz, Pelplin 1980 - VoxP 2 (1982) z. 3, 400-402.

3. Św. Augustyn, Doskonała sprawiedliwość człowieka, z łaciny przetłumaczył i wstępem opatrzył ks. W. Eborowicz, Pelplin 1982 - VoxP 4 (1984) z. 6-7, 431-434.

4. Sz. Pieszczoch, Kulturotwórcza inspiracja i wplyw chrześcijaństwa na rozwój antyku, Poznań 1992 - VoxP 10 (1990) z. 19, 964-966.

5. Św. Augustyn, Listy, tłum. W. Eborowicz, Pelplin 1991 - VoxP 11-12 (19911992) z. 20-23, 494-496.

6. F. Drączkowski, Miłość synteza chrześcijaństwa, Lublin $1991^{2}-227$, AK 86 (1993) z. 1, 191-193.

7. Saint Augustin, Lettres, traduction du Père W. Eborowicz, Pelplin 1991 - REAug 39 (1993) 491-492.

8. Pozostali w świecie, aby go przemieniać, „Pielgrzym” 6 (1995) nr 14, 7 [Recenzja: W sercu świata. Świeccy konsekrowani, red. M. Piotrowska - L. Rutkowska, Kraków 1994, ss. 117].

9. W sercu świata. Świeccy konsekrowani, red. M. Piotrowicz - L. Rutowska, Kraków 1994 - AK 126 (1996) z. 3 (523), 454-456.

10. A. Żurek, Duszpasterz końca epoki patrystycznej. Tożsamość kapłana $w$ świetle „De vita contemplativa” Juliana Pomeriusza, Tarnów 1998 - VoxP 18 (1998) z. 34-35, 546-547.

11. M. Kosznicki, Kształcenie $i$ wychowanie w literaturze zachodniego chrześcijaństwa od I do IV wieku, Gdańsk 1999 - VoxP 19 (1999) z. 36-37, 534-536.

12. Tadeusz Kołosowski, Od wolności wyboru wyznania do przymusu religijnego. Ewolucja pogląów Biskupa Augustyna z Hippony podczas schizmy donatystycznej w Afryce Rzymskiej, Piła 2000 - VoxP 19 (1999) z. 36-37, 536-539.

13. A. Paciorek, Ewangelie synoptyczne, III: Ewangelia wedtug św. Marka, Tarnów 2002 -AK 138 (2002) z. 3 (559), 634-636.

14. A. Paciorek, Elementy składniowe biblijnego języka greckiego, Lublin 2001 - AK 138 (2002) z. 3 (559), 636-637. 
15. P. Nehring, Dlaczego dziewictwo jest lepsze niż matżeństwo? Spór o ideat $w$ chrześcijaństwie zachodnim końca IV stulecia $w$ relacji Ambrożego, Hieronima i Augustyna, Toruń 2005 - VoxP 27 (2007) z. 50-51, 658-660.

16. J. Żelazny, Biskup Ojcem. Zarys eklezjologii syryjskiej na podstawie „,Konstytucji Apostolskich”, Kraków 2006 - VoxP 25 (2005) z. 48, 420-423.

17. S. Strękowski, Sofiologia św. Grzegorza z Nyssy. Elementy teologii trynitarnej $i$ antropologii $w$,Homiliach do Pieśni nad Pieśniami”, Kraków 2006 - VoxP 27 (2007) z. 50-51, 660-663.

18. A. Kijewska, Święty Augustyn, Myśli i ludzie, Warszawa 2007 - VoxP 27 (2007) z. 50-51, 663-664.

19. T. Gacia, Metaforyka agonistyczna w literaturze łacińskiej chrześcijańskiego antyku, Kielce 2007 - VoxP 29 (2009) z. 53-54, 711-713.

20. S. Reszka, Żywot Księdza Stanisława Hozjusza (Polaka) Kardynała Świętego Kościoła Rzymskiego, Penitencjarza Wielkiego i Biskupa Warmińskiego, Wstęp, przekład z wydania w Oliwie w 1690 r. i komentarze Jadwiga Ambrozja Kalinowska OSB, Olsztyn 2009 - VoxP 29 (2009) z. 53-54, 784-785.

\section{G. Sprawozdania}

1. Doroczne spotkanie Sekcji Filologicznej, VoxP 4 (1984) z. 6-7, 469-470.

2. Spotkanie Sekcji Filologicznej - Białystok 1986, VoxP 6 (1986) z. 11, 743-746.

3. Spotkanie Sekcji Filologicznej - Pelplin 1987, VoxP 7 (1987) z. 12-13, 530-532.

4. Doroczne spotkanie Sekcji Filologicznej - Gniezno 1988, VoxP 8 (1988) z. 15, 1132-1134.

5. Udział Sekcji Filologicznej w VI Kongresie Teologów Polskich, VoxP 9 (1989) z. 17, 991-993.

6. Doroczne XXV Spotkanie Sekcji Filologicznej (Kalwaria Zebrzydowska, 11-12 IX 1991), VoxP 11-12 (1991-1992) z. 20-23, 510-514.

7. Rodzina w starożytnym Rzymie (Bydgoszcz-Zacisze 20-21 V 1991), VoxP 11-12 (1991-1992) z. 20-23, 533-535.

8. Doroczne spotkanie Sekcji Filologicznej (Olsztyn, 14-15 IX 1993), VoxP 13-15 (1993-1995) z. 24-29, 648-650.

9. Doroczne spotkanie Sekcji Filologicznej (Radom, 12 IX 1995), VoxP 13-15 (19931995) z. 24-29, 694-695.

10. XXIX doroczne spotkanie Sekcji Filologicznej (Kielce, 10-11 IX 1996), VoxP 16 (1996) z. 30-31, 632-637.

11. Sprawozdanie z działalności Towarzystwa Naukowego KUL za okres od 1 stycznia 2001 do 31 grudnia 2001, „Summarium”30-31 (2001-2002) 235-254.

12. Sprawozdanie z działalności Towarzystwa Naukowego KUL za okres od 1 stycznia 2002 do 31 grudnia 2002, „Summarium” 30-31 (2001-2002) 255-273.

13. Sprawozdanie z działalności Towarzystwa Naukowego KUL za okres od 1 stycznia 2003 do 31 grudnia 2003, „Summarium” 32 (2003) 225-243.

\section{H. Biogramy i wspomnienia}

1. Była nie tylko profesorem. Wspomnienie o prof. Leokadii Małunowiczównie, w: Chrześcijanie, t. 13, red. B. Bejze, Warszawa 1984, 278-279.

2. Ks. Wacław Eborowicz, VoxP 8 (1988) z. 15, 557-561. 
3. Józef Kuranc (1904-1989), VoxP 9 (1989) z. 17, 1014-1017.

4. Wspomnienie o śp. ks. dr. hab. Wacławie Eborowiczu, „Pielgrzym” 5 (1994) nr 25, 6.

5. Ksiadz Antoni Liedtke (1904-1994), VoxP 13-15 (1993-1995) z. 24-29, 729-732.

6. Ksiąd Wacław Eborowicz (1915-1994), VoxP 13-15 (1993-1995) z. 24-29, 725-728.

7. Ks. prof. dr hab. Henryk Wójtowicz - curriculum vitae, RH 44 (1996) z. 3, 5-9.

8. Vir magno intellectu et corde. Ksiadz Wacław Eborowicz (1915-1994), w: Księga Jubileuszowa. 350 lat Wyższego Seminarium Duchownego w Pelplinie, red. A. Nadolny, Pelplin 2001, 486-491.

9. Ksiądz Profesor Henryk Wójtowicz, „Przegląd Uniwersytecki KUL” 14 (2002) nr 4, 29.

10. Prof. Michał Kaczmarkowski jako badacz łaciny wczesnochrześcijańskiej, VoxP 23 (2003) z. 44-45, 765-769.

11. Vir magna sapientia et pietate, w: Świadek Chrystusowych cierpień (1 P 5, 1), red. J. Morawa, Studia - Papieska Akademia Teologiczna w Krakowie. Wydział Teologiczny t. 10, Kraków 2004, 107.

12. Eborowicz Wacław (biogram), w: Słownik Polskich Teologów Katolickich 19942003, red. J. Mandziuk, Warszawa 2006, 169-173.

13. Żyj nadal twórczo. Słowo na pogrzebie O. Rektora KUL i Prezesa TN KUL Prof. Dra hab. Mieczysława Alberta Krąpca, „Nasz Dziennik” z 20 V 2008, 11.

14. Rektor Uczelni Jezusa, „Pielgrzym” 22 (2011) nr 17, 16-17.

15. Vivas in Christo, anima candida. Stowo Prezesa Towarzystwa Naukowego Katolickiego Uniwersytetu Lubelskiego Jana Pawła II ks. prof. dr. hab. Augustyna Eckmanna, w: Abiit, non obiit. Księga poświęcona pamięci księdza profesora Antoniego Kościa SVD, red. A. Dębiński - P. Stanisz - T. Barankiewicz - J. Potrzeszcz - W.S. Staszewski - A. Szarek-Zwijacz - M. Wójcik, Lublin 2013, 11.

\section{Homilie i kazania}

1. Nasze posłanie w Kościele Powszechnym i Lokalnym, „Współczesna Ambona” 17 (1989) $\mathrm{nr}$ 2, 97-99.

2. Słowo Boże prowadzi do radości i jedności z braćmi, „Współczesna Ambona” 17 (1989) nr 1, 42-44.

3. Wdzięczność wyrazem szlachetności, „Współczesna Ambona” 17 (1989) nr 4, 23-24.

4. Życie wedtug Ewangelii, ,Współczesna Ambona” 17 (1989) nr 3, 77-78.

5. Bogu-chwała, ludziom - wolność, ,Współczesna Ambona” 18 (1990) nr 4, 14-16.

6. Trójca Święta początkiem i celem wszystkiego, „Współczesna Ambona” 18 (1990) nr 2, 88-90.

7. Wiara jako odwzajemniona miłość, „Współczesna Ambona” 18 (1990) nr 3, 34-35.

8. Chrześcijańskie rozumienie świata i historii, „Współczesna Ambona”, 19 (1991) nr 4, 42-44.

9. Chwalmy Boga w naszym ciele, ,Współczesna Ambona” 19 (1991) nr 1, 22-24.

10. Czas ucieka, wieczność trwa (tempus fugit, aeternitas manet), „Współczesna Ambona" 19 (1991) nr 1, 32-34.

11. Człowiek w rodzinie, „Współczesna Ambona” 19 (1991) nr 4, 103-105.

12. Veni Sancte Spiritus, ,Współczesna Ambona” 19 (1991) nr 2, 61-63.

13. W trosce o człowieka, „Współczesna Ambona” 19 (1991) nr 3, 16-19. 
14. Chrzest w nauczaniu Ojców Kościoła, „Współczesna Ambona” 20 (1992) nr 4, 101-102.

15. Osobliwe spotkanie, „Współczesna Ambona” 20 (1992) nr 2, 6-7.

16. Siła modlitwy $i$ wiary, ,Współczesna Ambona” 20 (1992) nr 4, 18-19.

17. Wielbi dusza moja Pana, „Współczesna Ambona” 20 (1992) nr 3, 43-45.

18. Wstapił do nieba, „Współczesna Ambona” 20 (1992) nr 2, 67-68.

19. Wyższa szkoła modlitwy, „Współczesna Ambona” 20 (1992) nr 3, 24-27.

20. Zawierzyć Bogu, „Współczesna Ambona” 20 (1992) nr 1, 57-59.

21. Bóg jest miłosierny, „Współczesna Ambona” 21 (1993) nr 4, 94-97.

22. Chrystus zmartwychwstaniem i życiem, „Współczesna Ambona” 21 (1993) nr 4, 77-78.

23. Jak On nas umiłowat, „Współczesna Ambona” 21 (1993) nr 1, 119-120.

24. Ku doskonałości na wzór Boga, „Współczesna Ambona” 21 (1993) nr 1, 68-71.

25. Ku życiu wiecznemu, „Współczesna Ambona” 21 (1993) nr 2, 121-122.

26. Ojednym Bogu w trzech Osobach, ,Współczesna Ambona” 21 (1993) nr 2, 82-86.

27. Do zobaczenia wkrótce [autoryzowany tekst homilii wygłoszonej w czasie pogrzebu ks. dra hab. Wacława Eborowicza], „Miesięcznik Diecezji Pelplińskiej” 3 (1994) z. 12, 35-39.

28. Któryś jest w niebie, „Współczesna Ambona” 22 (1994) nr 4, 85-88.

29. Wierzę w Ducha Świętego, „Współczesna Ambona” 22 (1994) nr 2, 83-89.

30. Chleba naszego powszedniego daj nam dzisiaj, „Współczesna Ambona” 23 (1995) $\mathrm{nr}$ 1, 92-99.

31. Eucharystia jako sakrament wieńczacy i przedtużajacy wtajemniczenie chrześcijańskie, „Współczesna Ambona” 23 (1995) nr 2, 123-125.

32. Ogień miłości, „Współczesna Ambona” 23 (1995) nr 3, 56-60.

33. Wzgardzony Król - naszą nadzieja, ,Współczesna Ambona” 23 (1995) nr 4, 67-68.

34. Chrystus - Redemptor hominis, ,Współczesna Ambona” 24 (1996) nr 4, 82-85.

35. Człowiek droga Kościoła, „Współczesna Ambona” 24 (1996) nr 3, 21-24.

36. Wielkie coroczne rekolekcje, „Współczesna Ambona” 24 (1996) nr 1, 69-73.

37. Zmartwychwstał Pan prawdziwie, ,Współczesna Ambona” 24 (1996) nr 2, 13-18.

38. Chrystus jedynym dobrym pasterzem, „Współczesna Ambona” 25 (1997) nr 2, 15-18.

39. Niepokalane Poczęcie, „Współczesna Ambona” 25 (1997) nr 4, 61-64.

40. Ofiara Chrystusa zapowiedziana w Izaaku, „Współczesna Ambona” 25 (1997) nr 1, 57-63.

41. Swiat szuka Chrystusa, „Współczesna Ambona” 25 (1997) nr 3, 31-35.

42. Nowe stworzenie i nowe przykazanie, „Współczesna Ambona” 26 (1998) nr 2, 54-56.

43. Słowo Wcielone wśród nas zamieszkało, „Współczesna Ambona” 26 (1998) nr 1, 9-12.

44. Życie doczesne droga do Boga, Homilia wygłoszona w czasie Mszy Świętej pogrzebowej za śp. prof. dr. hab. Michała Kaczmarkowskiego 2 kwietnia 2003 w Kościele Akademickim KUL, „Przegląd Uniwersytecki” 15 (2003) nr 3, 22-23.

\section{J. Inne}

1. Skorowidz słów greckich, w: Ewangelia wedtug św. Łukasza. Wstęp - przekład z oryginału - komentarz, opracował F. Gryglewicz, Poznań 1974, 431-432. 
2. W stużbie Ewangelii. Ewangelizacja, „Biuletyn Krajowej Konferencji Instytutów Świeckich" (1996) nr 5, 4-13.

3. Wykaz drukowanych prac ks. prof. dra hab. Henryka Wójtowicza w układzie chronologicznym, RH 44 (1996) z. 3, 11-20.

4. Laudacja z okazji przyznania nagrody im. ks. Idziego Radziszewskiego prof. dr hab. Annie Świderkównie przez Towarzystwo Naukowe KUL, „Przegląd Uniwersytecki KUL" 10 (1998) nr 5, 18-20.

5. Wierzę w Ducha Świętego, „Dla Boga i świata. Biuletyn Krajowej Konferencji Instytutów Świeckich" (1998) nr 3, 4-13.

6. Laudacja z okazji wręczenia prof. dr hab. Annie Świderkównie Nagrody im. Ks. I. Radziszewskiego, w: A. Świderkówna, Biblia a nauka, Lublin 1999, 5-20.

7. Rok 1999 - Rok Boga Ojca, Wprowadzenie do Kalendarza akademickiego KUL 1999, w: Kalendarz akademicki 1999, Lublin 1998, 3-6.

8. Bóg zwraca się do każdego po imieniu, „Przemienienie”, Biuletyn ISPP (2000) nr 56, 27-28.

9. Rok 2000 - Chrystus w Eucharystii, Wprowadzenie do Kalendarza akademickiego KUL 2000, w: Kalendarz Akademicki 2000, red. Cz. Krakowiak - J. Stępniak, Lublin 2000, 4-7.

10. Rok 2001 - Parafia i Ewangelizacja, w: Kalendarz akademicki 2001, red. Cz. Krakowiak - J. Stępniak, Lublin 2001, 4-9.

11. List Prezesa Towarzystwa Naukowego Katolickiego Uniwersytetu Lubelskiego Jana Pawła II, w: Ius et Fides. Ksiega Jubileuszowa z okazji siedemdziesiatych urodzin Profesora Jana Świtki, red. T. Guz - M. Kuć, Lublin 2006, 19.

12. Druk akcydensowy. Tekst dyplomu doktora honoris causa Akademii Medycznej w Lublinie dla ks. abpa Józefa Życińskiego - 1 X 2007.

13. List Prezesa Towarzystwa Naukowego Katolickiego Uniwersytetu Lubelskiego Jana Pawła II, w: „SCIO CUI CREDIDI. Księga pamiątkowa ku czci Księdza Profesora Mariana Ruseckiego w 65. rocznice urodzin, red. I. Ledwoń - K. Kaucha - Z. Krzyszowski - J. Mastej - A. Pietrzak, Lublin 2007, bez numeru.

14. List Prezesa Towarzystwa Naukowego Katolickiego Uniwersytetu Lubelskiego Jana Pawła II, VoxP 28 (2008) z. 52/1, 19.

15. Przemówienie wygłoszone przez ks. prof. dra hab. Augustyna Eckmanna, Prezesa Towarzystwa Naukowego KUL, 4 kwietnia 2008 roku na rozpoczecie dorocznego publicznego zebrania Towarzystwa Naukowego KUL, w: S. Wielgus, Historyczne koncepcje i paradygmaty uniwersytetu oraz jego model na dziś i na jutro, Lublin 2009, 7-13.

16. Fragmenty wystapienia Prezesa TN KUL ks. prof. dr. hab. Augustyna Eckmanna, podczas uroczystości wręczenia ks. prof. dr. hab. Bogusławowi Nadolskiemu TChr Nagrody im. Księdza Idziego Radziszewskiego, w: B. Nadolski, W kierunku antropologicznego wymiaru Eucharystii, Lublin 2012, 11-14.

17. List Prezesa Towarzystwa Naukowego Katolickiego Uniwersytetu Lubelskiego Jana Pawła II, w: Fructus Spiritus est Caritas. Ksiega jubileuszowa ofiarowana Księdzu Profesorowi Franciszkowi Draczkowskiemu z okazji siedemdziesiątej rocznicy urodzin, czterdziestopięciolecia święceń kapłańskich i trzydziestopięciolecia pracy naukowej, red. M. Wysocki, Lublin 2011, 34.

18. Druk akcydensowy. Tekst dyplomu Gratae Memoriae Signum Universitatis dla ks. bpa prof. dra hab. Jana Bernarda Szlagi - 2012. 
19. List Prezesa Towarzystwa Naukowego Katolickiego Uniwersytetu Lubelskiego Jana Pawła II, w: Ars omnia vincit. Studia z dziejów sztuki i kultury artystycznej, red. A. Bender - M. Kierczuk-Macieszko, Lublin 2012, 11-12.

20. Stowo Prezesa Towarzystwa Naukowego KUL ks. prof. dr. hab. Augustyna Eckmanna podczas uroczystości wręczenia ks. prof. dr. hab. Józefowi Krukowskiemu Nagrody im. Księdza Idziego Radziszewskiego, w: J. Krukowski, Prawo Unii Europejskiej a wartości chrześcijańskie, Lublin 2012, 7-14.

Zebrał ks. Marek Cieśluk - Lublin, KUL 
